\title{
Factors Affecting Hospital Choice for Rural Iowa Residents*
}

\author{
Kanlaya Jintanakul and Daniel Otto ${ }^{+}$
}

\begin{abstract}
This study uses Iowa Hospital Association records related to inpatient and outpatient procedures performed at rural Iowa hospitals to examine how institutional, locational, and individual characteristics affect choice of hospitals for rural residents. The rural residents most likely to bypass their local hospitals are younger people with private outpatient insurance already living a long distance from any hospital. Complex procedures and life-threatening illnesses can reduce the probability of choosing the nearest rural hospital. Rural residents also appear less likely to bypass the nearest rural hospital for outpatient services.
\end{abstract}

Keywords: rural hospitals, hospital choice, spatial markets, hospital bypassing

JEL Classifications: I11, R12, H44

\section{INTRODUCTION}

The nature of rural health care delivery has changed dramatically in recent decades because of continuing improvements in medical technologies, advances in transportation and communication systems, and rural demographic changes. Many medical procedures that once required lengthy hospital stays are now done on an outpatient basis. Improved roads and thirdparty payers have also made it easier for rural residents to seek medical services in more distant cities. In addition, declining rural populations and an increased concentration of elderly patients in the population have further reduced the potential patient base for many rural hospitals. In many cases, rural patients feel more comfortable seeking health services from full-service hospitals in urban areas. Hence, rural hospitals tend to be left with a distorted distribution of lowincome patients and are increasingly facing challenging financial situations.

The decreasing number of rural hospital visits poses a challenge for health policy makers. The continuing outmigration of potential hospital patients could cause an increase in hospital closures or mergers. Capalbo and Heggen (1990) show that, between 1980 and 1998, more than 300 rural hospitals closed nationwide. This drop in the number of rural hospitals creates a new challenge for health policy makers regarding their ability to provide a basic level of health care services to rural residents.

Policy efforts such as the Medicare Rural Hospital Flexibility Program (MRHFP) have attempted to maintain healthcare infrastructure in rural communities and to provide access to hospital-based acute care services. Under this program, rural hospitals with a Critical Access Hospital $(\mathrm{CAH})$ designation can receive cost-based reimbursement for inpatient and out-patient services. In spite of this financial advantage, many rural hospitals still struggle to remain viable as utilization rates decline because rural residents are bypassing local hospitals for services (Liu Bellamy, and McCormick, 2007). A study of 2,008 rural hospital closures occurring between

\footnotetext{
* The authors acknowledge helpful comments from Peter Orazem, Mark Imerman, and anonymous reviewers

+ Jintanakul is a graduate student and Otto is a Professor, both at the Department of Economics, Iowa State University. Contact: Daniel Otto, Department of Economics, Iowa State University, Ames, IA, 50011.Email: dmotto@iastate.edu.
}

(C) Southern Regional Science Association 2010. 
1990 and 2000 indicated that the major reasons for 46 percent of the closures were low occupancy rates and outside competition (Lawrence et al., 2003).

Understanding hospital choice decisions for inpatient and outpatient services can help health policy makers better evaluate current rural health policies, as well as helping them design a more cost-effective health care system for the future. ${ }^{1}$ The objective of their research is to provide rural communities and health policy makers with a better understanding of the factors affecting a patient's hospital choice for different types of health services. Identification of rural areas where residents' access to basic health care is sufficiently endangered is the major challenge in designing Federal rural-health policies (office of Technology Assessment, 1990). Exploring patients' behaviors helps decision makers design better health policies, allocate health resources more efficient, and ensure basic levels of adequate health care for residents in both rural and urban areas. In addition, several studies have found that access to health and medical services often can play an important role in attracting and retaining business and jobs since local hospitals typically spend sizeable portions of their revenues on goods and services produced by local businesses (Cordes, 1997). Thus, rural hospitals not only ensure basic levels of health care, but can also assert some economic vitality into the communities in which they are located.

Using a conditional logit model of seven hospital choices, Adams et al. (1991) analyzed over 12,000 choices made by Medicare beneficiaries in 1986. They found that a hospital's scope of service and teaching activity appears to have positive effects on the choices made by Medicare beneficiaries. A hospital's distance from a beneficiary's home appears to have a negative effect on its selection, especially for older patients. While patients older than 85 years tended to choose a hospital closer to home, patients with severe illness preferred larger urban or rural hospitals over smaller rural hospitals. Similarly, a study by Goodman et al. (1997) using Poisson regression to analyze the relationship between travel time and likelihood of hospitalization and found that distance to a hospital is an important factor in determining hospitalization patronage rates.

Rural residents increasingly bypassed rural hospitals over the past three decades. Using county-level data from New York, Hogan (1988) found that rural residents tend to travel to urban hospitals when they incur a severe illness, although elderly rural residents were less likely to do so. Bronstein and Morrisey (1990) found that Medicaid-eligible rural patients in Alabama travel further for obstetric care than did other patients. Perceptions of better care at urban hospitals, in particular, led rural dwellers to travel farther. Rural hospitals tended to be perceived as an inferior good among rural obstetric patients. As their income increased by a percent, they tended to travel four percent further for obstetric care. ${ }^{2}$

Radcliff et al. (2003) studied inpatient discharge data in California, Florida, New York, Maine, Oregon, South Carolina, and Washington for 1991 and 1996. In their study, rural patients were defined as patients whose postal ZIP codes were consistent with a nonmetropolitan county, and bypass behavior was defined as discharge from a hospital between 15 and 1,000 miles from the closest facility. Radcliff et al. analyzed multiple geographic areas, types of payer, and types of diagnosis in an attempt to overcome limitations of previous studies where single geographic

\footnotetext{
${ }^{1}$ Adams et al. (1991) provide a good discussion about related policies and previous studies.

${ }^{2}$ Morgan, Turner, and Savitz (1999) provide a good literature review of factors influencing obstetric care. Economics and sociodemographic factors such as cost of care, distance to care, patient perception of quality, and patient age, education, race, and place of residence influence the hospital selection for obstetric care.
} 
area, type of payer, or type of diagnosis was examined. Through descriptive analysis, they found the overall bypass rate to be 30 percent, with little change between 1991 and 1996. The bypass rate was higher among patients with managed care or commercial insurance and lower among Medicare patients or uninsured patients. They also found that patients seeking general medical or obstetrical care had a lower bypass rate compared to patients seeking complex medical general surgery or specialty surgery services. They conclude that, although rural patients perceived local rural hospitals as a viable option for general inpatient care services, they preferred other facilities for more complex treatments.

Our study differs from previous studies in several ways. First, our definition of a rural resident differs from that in previous studies. In order to better identify rural hospital bypass behavior, we define rural residents as residents whose nearest hospital is classified as either rural or a rural referral hospital. To classify hospitals as rural or rural referral hospitals, we follow the classification provided by the Iowa Hospital Association (2003), where rural hospitals are those located in nonmetropolitan areas. Second, we focus on studying the hospital choice of rural residents rather than of all residents. Hence, hospitals are classified into three different types nearest rural hospital, nearest urban hospital, and other hospitals. Third, we analyze both inpatient and outpatient services provided by hospitals, using a complete set of statewide hospitalization data. Fourth, our database allows us to study a variety of illnesses and affiliated payments rather than to study a specific type of illness or type of insurance payment as has been the focus of most previous studies. Finally, we use a data set that includes information about hospital characteristics, patient demographics such as economic and health status, and regional spatial characteristics. Many previous studies have approximated patient characteristics using socio-economic data of patients' postal ZIP codes. By combining these other elements in this study we are better able to scrutinize factors affecting the choices of rural residents for a full range of rural hospital services.

\section{RURAL HOSPITAL UTILIZATION PATTERNS}

Iowa Hospital Association records regarding patient visits in 2002 were used to track both inpatient visits (Map 1) and outpatient visits (Map 2). ${ }^{3}$ These maps provide a convenient visualization of patient hospitalization behavior. The amoebae-like shapes represent hospital proximity areas where the probability of a patient at any location patronizing a given hospital is greater than 50 percent. Hospitals located in the same city are combined into one hospital area. These proximity areas are estimated using GIS techniques involving a gravity model. ${ }^{4}$ Areas not included in these amorphous regions represent locations where the probability of potential patients going to any hospital is less than 50 percent (Imerman et al., 2004). To create these maps, hospitals located in the same city were combined into a single hospital area. For example, multiple hospitals in Cedar Falls and Waterloo were combined into one hospital area due to their close proximity. In addition, the proximity area of Council Bluffs is relatively small because of the short distance to metropolitan Omaha, Nebraska. The density of dots around Council Bluffs is fairly low since the data used for this study include only patients patronizing hospitals in Iowa.

\footnotetext{
${ }^{3}$ Colored versions of these maps are available upon request from the authors or at: http://www.econ.iastate.edu/research/webpapers/paper_12630_06023.pdf.

${ }^{4}$ For more details about the gravity model, see Imerman et al. (2004)
} 
Hence, Iowa patients hospitalized in other states - the case of many Council Bluffs residentswere not included in this study.

Each dot in these maps represents ten patient visits and each can be categorized into one of four categories. The "In-In" category represents patients who live inside a hospital's market area and chose services at that hospital. The "In-Out" category represents patients who live within a given hospital market area but who chose a hospital outside that area. The "Out-Near" category represents patients whose ZIP codes are not within any hospital market areas and who chose to use the nearest hospital. The "Out-Far" category represents patients whose ZIP codes are not within a hospital market area and who did not choose the nearest hospital. As a result, the "In-Out" and "Out-Far" categories approximate hospital bypass behavior by rural residents.

While Map 1 and Map 2 are very similar, a number of interesting differences can be noted. First, small hospitals are represented mostly by small amorphous shapes that are mostly filled with green dots (In-Out). This pattern implies that patients residing inside small hospital areas tend to bypass their local hospitals for more distant alternatives. Second, the number of blue dots (Out-Near) is relatively small, which indicates that patients living outside a hospital market area are less likely to choose the nearest hospital. Exceptions are those areas relatively close to medium and large hospitals. Finally, the number of green dots (In-Out) from the inpatient map is significantly higher than that from the outpatient map, especially in areas surrounding the larger cities of Des Moines, Fort Dodge, and Sioux City. This indicates that smaller hospitals in the surrounding rural areas are faced with the dilemma of local patients bypassing them, a phenomenon that is more serious for inpatient visits than for outpatient visits.

Map 1: Inpatient Visits in Iowa, 2002

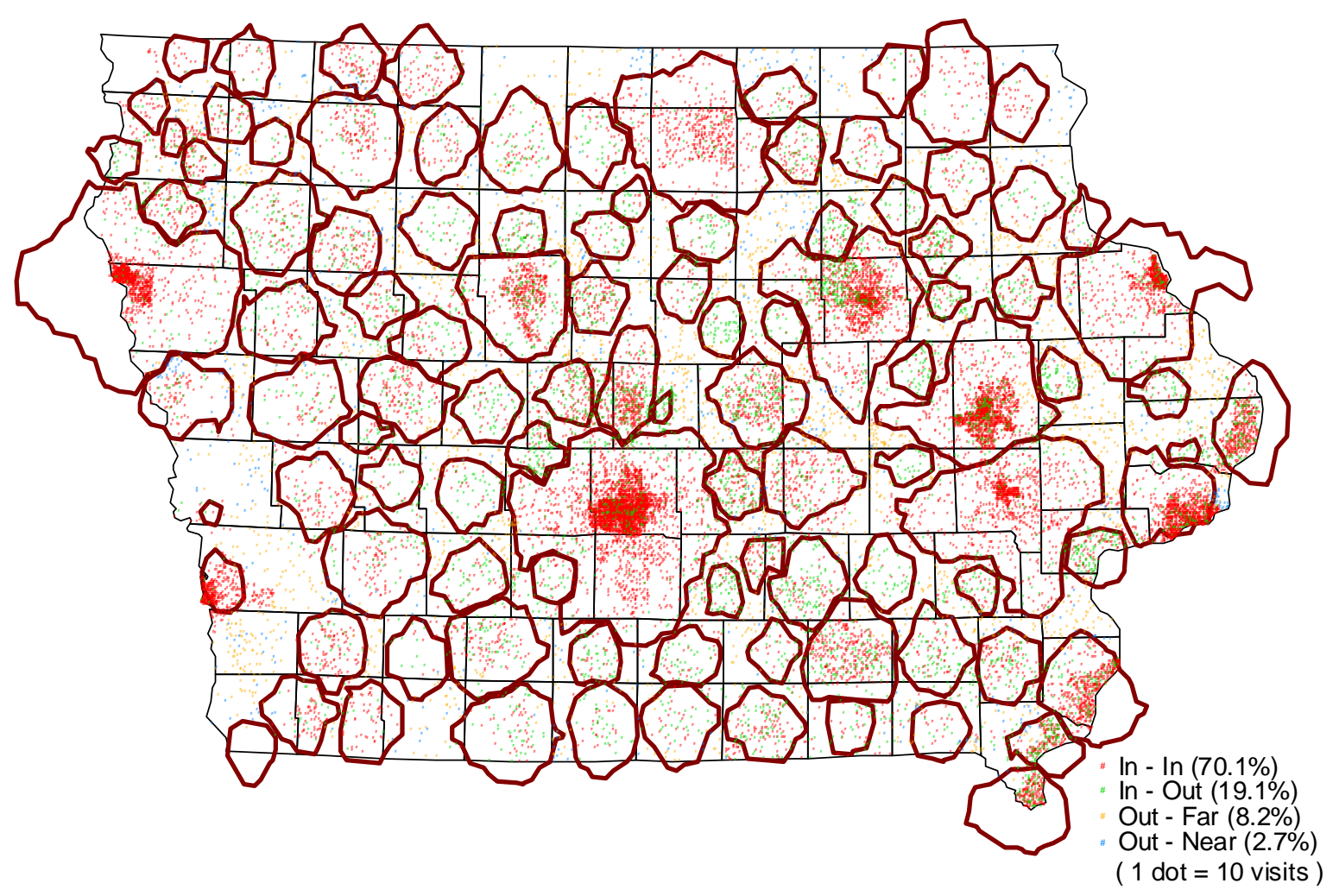

(C) Southern Regional Science Association 2010. 
Map 2. Outpatient Visits in Iowa, 2002

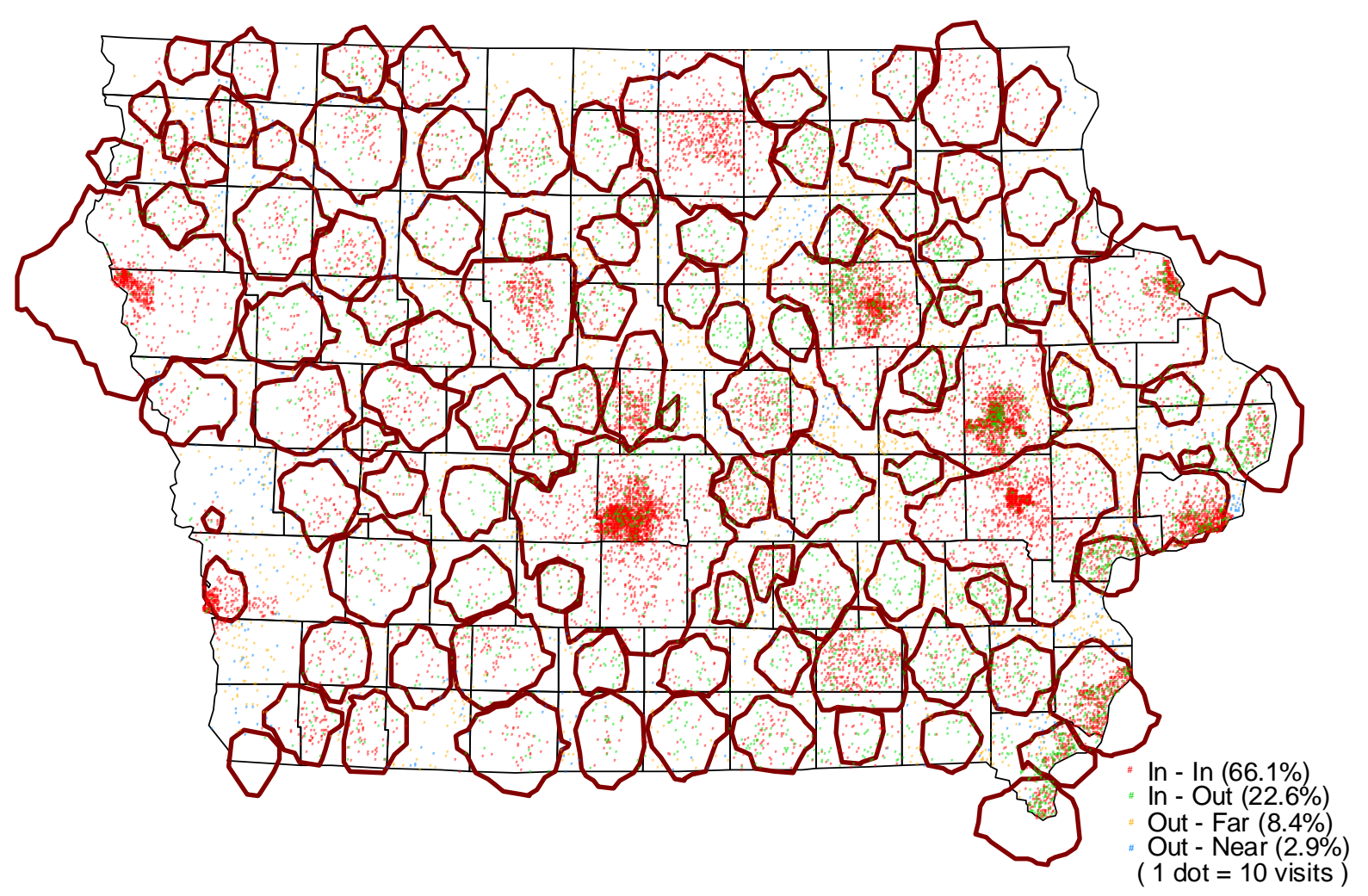

According to both inpatient and outpatient maps, small hospital market areas contain more green dots than do larger hospital areas. Hence, smaller hospitals tend to be bypassed by their local residents in greater proportion than are larger hospitals. Our primary objective therefore is to identify factors that influence this pattern of bypassing. In addition, since bypassing behavior appears to be comparatively more frequent for small hospitals than for larger ones (and, hence, crucial to small hospitals' financial health), we focused our study on the bypassing behavior of rural residents. ${ }^{5}$ Although the "In-Out" and "Out-Far" categories in these maps show the bypassing behavior, these classifications are based on a gravity model's conception of a hospital market area and not necessarily the rural resident's nearest hospital. For example, a patient might live in a rural ZIP code located just inside the border of a Des Moines hospital's market area. Therefore, although the nearest hospital is a rural hospital, the patient will be classified as an "In-In" category on the maps (not apparent bypass behavior). But in our statistical analysis, she or he will be classified as having bypassed the nearest rural hospital.

\section{MODEL}

The prospective patient's hospital choice is modeled as a discrete-choice situation in which each patient can choose among three hospital choices: choice 1 - the nearest urban hospital, choice 2 - the nearest rural hospital, and choice 3 - other hospitals. Relying on the random utility model (RUM), for the $i$ th patient facing $J$ hospital choices, the utility of choice $j$ is

\footnotetext{
${ }^{5}$ Rural residents are residents whose nearest hospital is classified as a rural hospital.
} 


$$
U_{i j}=\beta^{\prime} x_{i j}+\varepsilon_{i j}
$$

where $\mathrm{X}_{\mathrm{ij}}$ represents variables that the $i^{\text {th }}$ patient obtains from the $j^{\text {th }}$ choice and $\varepsilon_{i j}$ is a random disturbance. Considering the observed characteristics, equation (1) can be rewritten as

$$
U_{i j}=V_{i j}\left(N_{i}, D_{j}, E_{i}, S_{i}\right)+\varepsilon_{i j}
$$

where

$$
\begin{array}{ll}
N & \text { represents demographic characteristics } \\
D & \text { represents choice characteristics } \\
E & \text { represents economic status } \\
S & \text { represents health status } \\
\varepsilon & \text { represents the unobserved components. }
\end{array}
$$

A patient makes choice $j$ if the utility received from choice $j$ is greater than the utility received from each of the other choices. Hence, the probability of a patient choosing choice $j$ is equal to the probability that the utility of choice $j$ is greater than the utility of any of the other choices, or

$$
\operatorname{Pr}\left(U_{i j}>U_{i k}\right) \text { for all } k \neq j
$$

Assuming identically and independently extreme value error terms, the probability that the patient will choose hospital $j$, according to a multinomial logit model (MNL), can be calculated by

$$
\operatorname{Pr}(Y i=j)=\frac{e^{\beta^{\prime} x_{i j}}}{\sum_{j=1}^{J} e^{\beta^{\prime} x_{i j}}}
$$

By fitting data into the theoretical model shown in (2), coefficients can be estimated. Nonetheless, in order to estimate the multinomial logit model, one alternative must be selected as a base logit against which others are contrasted. ${ }^{6}$ We chose the nearest rural hospital (Choice 2) to be the base logit because it facilitated interpretation of results.

Parameter estimates from multinomial logit models are interpreted as the change of the log-odds ratio as a result of the change in the independent variable relative to the base logit (Hausman and McFadden, 1984). That is, a positive (negative) coefficient means that the relative probability of choosing hospital alternative $j$ increases (decreases) relative to the probability of selecting the nearest rural hospital. Except for dummy variables, this interpretation does not explain much about the impact of independent variables. Therefore, the "marginal effect" is also computed to provide a better intuitive interpretation. Marginal effects can be interpreted as a change of probability for alternative $j$ as a result of one unit change of $x_{k}$. Regardless of its violation of the Independence of Irrelevant Alternatives (IIA), the multinomial logit model is widely accepted and used to model discrete choice behaviors (Greene, 2000).

\footnotetext{
${ }^{6}$ The base group can be arbitrary chosen.
} 


\section{DATA AND VARIABLES}

The primary data source for this study is the Iowa Hospital Association's 2002 inpatient and outpatient database for Iowa. This database provides one record for every inpatient admission and outpatient visit to Iowa hospitals during the 2002 calendar year. Newborn infant discharges were excluded, and only visits of rural Iowa residents ${ }^{7}$ to Iowa hospitals were included. Out of 364,949 inpatient records and 229,467 outpatient records, only 162,248 and 132,828 records contain complete information with respect to all included variables for inpatients and outpatients, respectively. Based on our initial analysis on available information of missing observations, they do not appear to be clustered by age, diagnosis, ZIP code, gender and income. Hence, we assume that the workable data is a good representation of the population with no obvious selection bias problem. We further assume that each observation is independent from each other.

Like Bronstein and Morrisey (1991), we used Euclidean distances between ZIP code centroids to determine an individual's nearest hospital. The nearest urban hospital is then determined as Choice 1 and the nearest rural hospital as Choice 2. Other hospitals are classified as Choice 3. This approach was applied to both the in- and out-patient models.

Demographic characteristics, including age (elder65), sex (female) and race (nonBlkWht), are widely viewed as significantly influencing hospital choices. While, elderly population and non-black/white population are more likely to utilize local hospitals, whether female or male patients are likely to bypass their local hospitals is more difficult to determine. The impact of the sex variable would likely vary depending on other variables such as types of diagnosis. We also control for economic variables in our model. To proxy job quality and economic status of patients, we include source of payment (payMedicaidUninsure) for health care. Source of payment indicates whether the resident has private health insurance, Medicare, or no coverage at all. Patients with better health insurance plant tend to consider less about the cost of care and may be more likely to attend urban hospitals which are more expensive. We also use median household income (HHmedianInc) to test the hypothesis that higher-income households are more likely to bypass their local rural hospitals.

The model includes variables representing an individual's health status including principal diagnosis (diagLifeThreaten), type of admission (admissEmergency and admissElect), and principal procedure type (procEye, procDiges and procThera) were taken directly from the data set. Patients with non-life-threatening diagnoses, patients who need simple procedures or patients with emergency needs are more likely to utilize their local hospital. To transform these variables into a workable dataset, we reclassified each detail category into a broader group using the following steps. First, according to McNamara (1998), principal diagnoses were classified into three broad categories, including chronic/degenerative, life threatening, and other. Second, the type of admission was classified into three categories, namely, emergency, elective, and other. Third, according to Clinical Classification Software (CCS), the principal procedures were classified into 16 diagnosis-related categories. For the Outpatient Model, the three most frequent diagnostic categories, accounting for more than 70 percent of outpatients, were chosen as a subset and then used as independent control variables. This classification helps separate

\footnotetext{
${ }^{7}$ A patient is considered a rural resident if his/her nearest hospital is classified as a rural hospital.
} 
procedures related to basic diseases from those of complex diseases. Still, almost half of all inpatient records do not contain information about the principal procedure. Therefore, the Diagnosis Related Groups (DRG) code is used instead. This DRG classification, though somewhat more subjective, has the same advantages as the CCS classification.

The choice characteristics include the capacity utilization ratio (nearHosCapa) and number of physicians (nearHosPhy) at the nearest rural hospital. These variables are meaningful indicators of quality and availability of rural health services. In addition, a distance to the nearest rural hospital (straightDistance) is included. This distance data are calculated using the linear procedure described earlier. Though straight-line distance is not an exact measurement of travel time or road miles, Phibbs and Luft (1995) have shown that straight-line distance is highly correlated to travel time or road miles. Brief descriptions of all variables used in the Inpatient and Outpatient Models are described in Table 1.

Table 1. Description of Study Variables

\begin{tabular}{|c|c|c|}
\hline & Variable & Description \\
\hline \multicolumn{3}{|l|}{ Dependent } \\
\hline & hospital choice & 1 - nearest urban, 2 - nearest rural, and 3 - others \\
\hline \multicolumn{3}{|l|}{ Independent } \\
\hline & Demographic & \\
\hline & elder65 & $1-$ age $>=65,0-$ otherwise \\
\hline & female & 1 - female, 0 - otherwise \\
\hline & raceNonWhite & 1 - non white, 0 - white \\
\hline & Choice & \\
\hline & straightDistance & $\begin{array}{l}\text { Straight line distance from patient zip code to the nearest } \\
\text { rural hospital }\end{array}$ \\
\hline & nearHosCapa* & Capacity utilization ratio of the nearest rural hospital \\
\hline & nearHosPhy & Numbers of physicians of the nearest rural hospital \\
\hline & Economics Status & \\
\hline & payPrivate & $\begin{array}{l}1 \text { - Source of payment: Blue Cross, commercial, worker } \\
\text { compensation, HMO, and PPO, } \\
0 \text { - non-private source of payment (public and self pay) }\end{array}$ \\
\hline & HHmedianInc & Household median income (by ZIP code) \\
\hline & Health Status & \\
\hline & diagLifeThreaten & 1 - Principal diagnosis: Life threatening, 0 - otherwise \\
\hline & admissEmergency & 1 - Type of admission: Emergency, 0 - otherwise \\
\hline & admissElect & 1 - Type of admission: elective, 0 - otherwise \\
\hline & complexOper & 1 - Complex procedures, 0 - otherwise \\
\hline & & Principal procedure: 1 - operations on the digestive \\
\hline & procDiges & system, 0 - otherwise \\
\hline & procThera & $\begin{array}{l}\text { Principal procedure: } 1 \text { - miscellaneous diagnostic and } \\
\text { therapeutic procedures, } 0 \text { - otherwise }\end{array}$ \\
\hline & & Principal procedure: 1 - operations on the eye, \\
\hline & procEye & 0 - otherwise \\
\hline
\end{tabular}

* Capacity utilization ratio is the ratio of the actual utilization level to the full ability level 
Table 2. Summary Statistics of the Study Variables

\begin{tabular}{|c|c|c|c|c|c|c|c|c|c|c|c|}
\hline & & \multicolumn{6}{|c|}{ Inpatients } & \multicolumn{4}{|c|}{$\begin{array}{l}\text { Outpatients } \\
\end{array}$} \\
\hline & & \multirow[b]{2}{*}{$\begin{array}{c}\text { All } \\
\text { procedures } \\
\text { Mean }\end{array}$} & \multicolumn{5}{|c|}{ By procedures } & \multirow[b]{2}{*}{$\begin{array}{c}\text { All procedures } \\
\text { Mean }\end{array}$} & \multicolumn{3}{|c|}{ By procedures } \\
\hline & & & $\begin{array}{c}\text { Obstetrical } \\
\text { procedures } \\
\text { Mean }\end{array}$ & $\begin{array}{c}\text { Miscellaneous } \\
\text { diagnostic \& } \\
\text { Therapeutic } \\
\text { Procedures } \\
\text { Mean } \\
\end{array}$ & $\begin{array}{c}\text { Operations on the } \\
\text { musculoskeletal } \\
\text { system } \\
\text { Mean } \\
\end{array}$ & $\begin{array}{l}\text { Operations on the } \\
\text { digestive system } \\
\text { Mean }\end{array}$ & $\begin{array}{l}\text { Operations on the } \\
\text { cardiovascular } \\
\text { system } \\
\text { Mean } \\
\end{array}$ & & $\begin{array}{l}\text { Operations on } \\
\text { the eye } \\
\text { Mean }\end{array}$ & $\begin{array}{l}\text { Operations on } \\
\text { the digestive } \\
\text { system } \\
\text { Mean }\end{array}$ & $\begin{array}{c}\text { Miscellaneous } \\
\text { diagnostic \& } \\
\text { Therapeutic } \\
\text { Procedures } \\
\text { Mean } \\
\end{array}$ \\
\hline \multicolumn{12}{|c|}{ Dependent variables* } \\
\hline & choice 1 & 29,332 & 3,052 & 3,074 & 4,024 & 2,966 & 5,509 & 23,385 & 2,189 & 10,431 & 3,318 \\
\hline & choice 2 & 57,693 & 7,025 & 8,206 & 3,400 & 7,196 & 2,372 & 65,207 & 9,438 & 34,751 & 6,648 \\
\hline \multirow{7}{*}{ Demographic } & choice 3 & 45,803 & 5,110 & 4,625 & 4,900 & 4,527 & 6,679 & 44,236 & 6,888 & 17,332 & 7,485 \\
\hline & elder65 & 0.525 & & 0.588 & 0.613 & 0.525 & 0.628 & 0.437 & 0.847 & 0.421 & 0.432 \\
\hline & elaeros & $(0.500)$ & & $(0.492)$ & $(0.487)$ & $(0.499)$ & $(0.483)$ & $(0.496)$ & $(0.360)$ & $(0.494)$ & $(0.495)$ \\
\hline & female & 0.599 & & $\begin{array}{l}0.4543 \\
0.543\end{array}$ & $\begin{array}{r}0.4017 \\
0.587\end{array}$ & 0.568 & $\begin{array}{r}0.403) \\
0.406\end{array}$ & 0.557 & 0.624 & $\begin{array}{r}0.450 \\
0.550\end{array}$ & 0.511 \\
\hline & Hemare & $(0.490)$ & & $(0.498)$ & $(0.492)$ & $(0.495)$ & $(0.491)$ & $(0.497)$ & $(0.484)$ & $(0.497)$ & $(0.500)$ \\
\hline & raceNonWhite & 0.170 & 0.220 & 0.100 & 0.190 & 0.170 & 0.310 & & & & \\
\hline & & $(0.380)$ & $(0.414)$ & $(0.306)$ & $(0.395)$ & $(0.377)$ & $(0.463)$ & & & & \\
\hline Choice & straightDistance & 5.26 & 5.41 & 4.85 & 5.74 & 5.58 & 5.81 & 5.34 & 5.21 & 5.36 & 5.30 \\
\hline & & (5.96) & $(6.02)$ & (5.92) & $(6.11)$ & (6.07) & (6.17) & (5.96) & (5.87) & (5.98) & $(6.00)$ \\
\hline & nearHosCapa & 33.26 & 33.23 & 33.64 & 32.66 & 33.03 & 33.08 & 32.33 & 31.88 & 32.03 & 33.36 \\
\hline & & $(15.75)$ & $(15.94)$ & $(15.31)$ & $(15.49)$ & $(15.68)$ & $(15.89)$ & (15.46) & $(15.39)$ & $(15.22)$ & $(15.63)$ \\
\hline & nearHosPhy & 46.73 & 49.14 & 46.91 & 47.86 & 47.32 & 51.06 & 48.57 & 48.04 & 47.13 & 55.13 \\
\hline \multirow{2}{*}{\multicolumn{12}{|c|}{ Economics Status }} \\
\hline & & & & & & & & & & & \\
\hline & payPrivate & $\begin{array}{r}0.330 \\
(0.470)\end{array}$ & $\begin{array}{r}0.670 \\
(0.469)\end{array}$ & $\begin{array}{r}0.240 \\
(0.428)\end{array}$ & $\begin{array}{r}0.300 \\
(0.459)\end{array}$ & $\begin{array}{r}0.350 \\
(0.477)\end{array}$ & $\begin{array}{r}0.270 \\
(0.446)\end{array}$ & $\begin{array}{r}0.460 \\
(0.498)\end{array}$ & $\begin{array}{r}0.130 \\
(0.341)\end{array}$ & $\begin{array}{r}0.500 \\
(0.500)\end{array}$ & $\begin{array}{r}0.400 \\
(0.490)\end{array}$ \\
\hline & HHmedianInc & 37,000 & 37,567 & 36,573 & 37,128 & 37,112 & 37,389 & 37,130 & 36,725 & 37,273 & 36,901 \\
\hline & & $(4,750)$ & $(4,862)$ & $(4,198)$ & $(4,788)$ & $(4,834)$ & $(5,031)$ & $(4,683)$ & $(4,446)$ & $(4,756)$ & $(4,424)$ \\
\hline \multirow{13}{*}{ Health Status } & diagLifeThreate & 0.230 & & 0.270 & 0.020 & 0.120 & 0.790 & 0.080 & 0.000 & 0.010 & 0.300 \\
\hline & & $(0.420)$ & & $(0.444)$ & $(0.138)$ & $(0.328)$ & $(0.406)$ & $(0.271)$ & $(0.025)$ & $(0.115)$ & $(0.456)$ \\
\hline & admissEmergency & 0.280 & 0.040 & 0.290 & 0.200 & 0.290 & 0.270 & & & & \\
\hline & adminstimgtrity & $(0.448)$ & $(0.186)$ & $(0.452)$ & $(0.397)$ & $(0.455)$ & $(0.442)$ & & & & \\
\hline & admissElect & $\begin{array}{r}0.450 \\
0.350\end{array}$ & 0.490 & $\begin{array}{r}0.470 \\
0.270\end{array}$ & 0.550 & $\begin{array}{r}0.450 \\
0.350\end{array}$ & 0.470 & & & & \\
\hline & ACIIISSETE & $(0.478)$ & $(0.500)$ & $(0.446)$ & (0.497) & $\begin{array}{l}(0.477) \\
\end{array}$ & $(0.499)$ & & & & \\
\hline & complexOper & 0.500 & 0.690 & 0.480 & 0.160 & 0.570 & 0.860 & & & & \\
\hline & & $(0.500)$ & $(0.464)$ & $(0.500)$ & $(0.366)$ & $(0.496)$ & $(0.346)$ & & & & \\
\hline & procDiges & & & & & & & $\begin{array}{r}0.470 \\
0.490\end{array}$ & & & \\
\hline & procThera & & & & & & & $\begin{array}{r}(0.499) \\
0.130\end{array}$ & & & \\
\hline & & & & & & & & $(0.338)$ & & & \\
\hline & procEye & & & & & & & 0.140 & & & \\
\hline & & & & & & & & $(0.346)$ & & & \\
\hline
\end{tabular}

Notes: Standard deviation is in parenthesis. *Numbers of observation are those for each hospital choice

(C) Southern Regional Science Association 2010. 
Table 2 shows a statistical summary of both inpatient and outpatient data as well as the five $^{8}$ most frequently used procedures for inpatients and the three ${ }^{9}$ most frequently used procedures for outpatients. Except for straightDistance, nearHosCapa, nearHosPhy and HHmedianInc, all other independent variables are dummy variables whose means can be interpreted as percentage of data having dummy values equal to one. The value of straightDistance represents the distance to the nearest rural hospital. Hence, the value of 5.26 for inpatients means that, on average, the rural hospital is approximately 5.26 miles from the inpatient ZIP code. The units for nearHosCapa, nearHosPhy and HHmedianInc are percentages, numbers of physicians at the nearest rural hospital, and dollars, respectively. These variables have interpretations similar to those described for straightDistance.

\section{RESULTS}

Table 3 gives estimated coefficients of the logs of the odd ratios for the Inpatient and Outpatient models, and Table 4 reports estimated results separately for five inpatient procedure and three outpatient procedure categories. The results show that all coefficients are statistically significant in both tables.

As mentioned in the Model section, the sign of the estimated coefficients can only be interpreted meaningfully with respect to the base choice, i.e., the nearest rural hospital. A negative (positive) coefficient means that the independent variable has a positive (negative) effect on the base choice (in our case, the nearest rural hospital) compared to that hospital choice. The elderly residents (elder65) variable appears to be negative in most models, indicating that these patients are less likely to bypass their nearest rural hospital in favor of the nearest urban hospital or other hospitals. This result is consistent with previous studies and can be explained in terms of mobility issues and long term loyalty to local hospitals. Gender (female) also appears to play a key role for rural hospitals, with women significantly less likely to choose an urban hospital. Several reasons may have led to this finding, e.g., demographic structure of rural residents skewed toward more single elderly women and different health services provided for different genders.

The estimated coefficients for individual inpatient procedures, except for cardiovascular procedures, were generally consistent with the aggregated results. Elderly patients and women were more likely to bypass nearest rural hospitals for cardiovascular procedures. Higher scores for the measures of hospital capacity and quality (nearHosCapa, nearHosPhy) in the model for cardiovascular procedures were associated with a higher probability of bypassing the nearest rural hospital, also in contrast to the pattern for the aggregate model. The coefficients for income and private insurance in the model for cardiovascular procedures were consistent with the other models, indicating that higher-resource rural residents with private insurance are more likely to bypass nearest rural hospitals.

The positive sign for race (raceNonWhite) in most models indicates that non-white residents are more likely to bypass and select the nearest urban hospital or other hospitals rather than the nearest rural hospital. This could be related to the fact that there are significant numbers.

\footnotetext{
${ }^{8}$ These five procedures contribute to more than 50 percent of all inpatients admissions.

${ }^{9}$ These three procedures contribute to more than 70 percent of all outpatient visits.
} 
Table 3. Multinomial Logit Model of Hospital Choices of Rural Residents

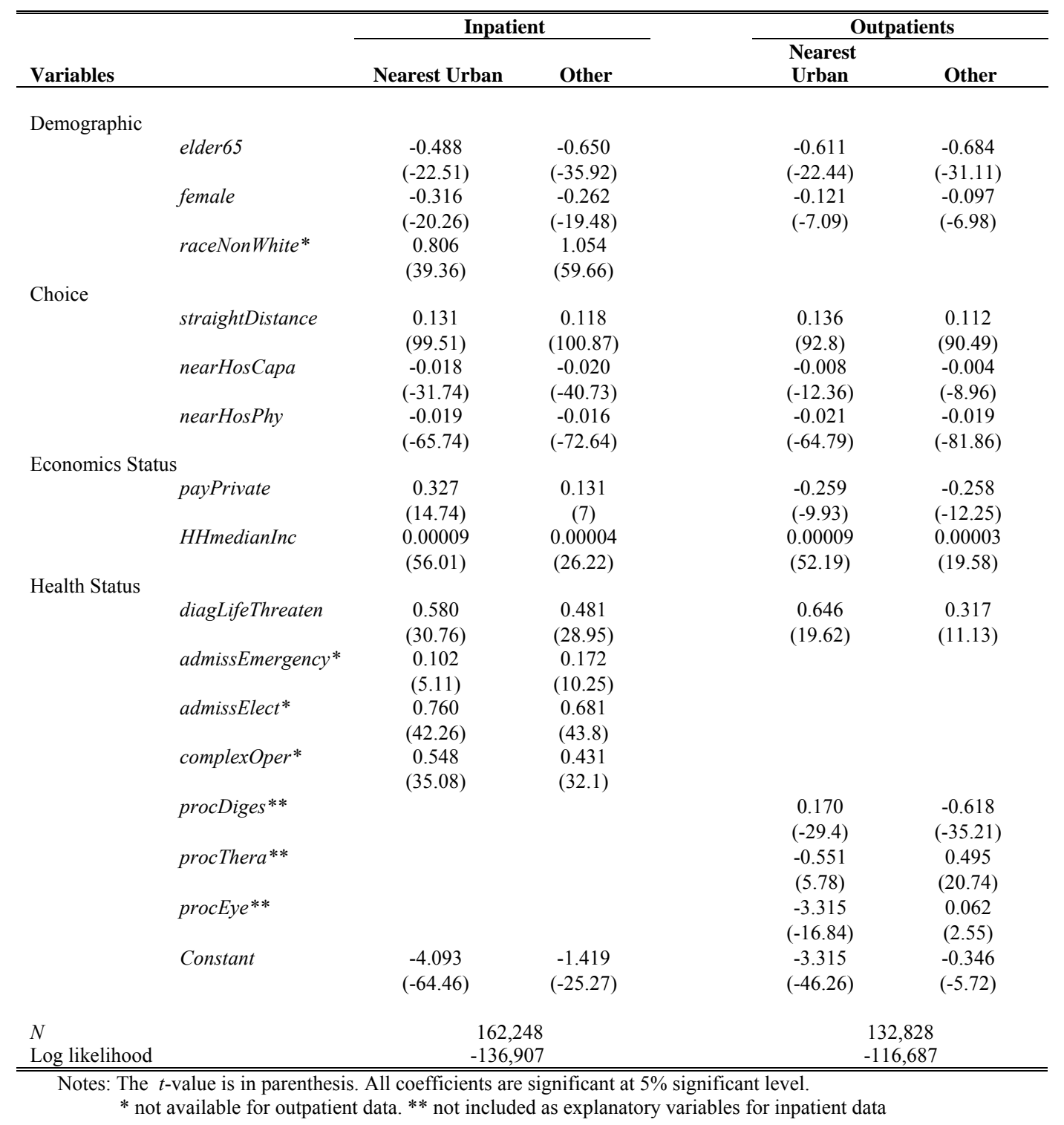

of Hispanic and Native American populations who may live in a rural area because of lower housing costs, but commute to available jobs in urban areas.

Consistent with results found in the literature (Adam et al., 1991; Goodman et al., 1997), our spatial distance measure (straightDistance) has a positive coefficient, implying that a longer distance to the nearest rural hospital is associated with a higher rate of utilizing the nearest urban or other hospitals. Negative coefficients for our rural hospital capacity measures (nearHosCapa) and (nearHosPhy) indicate that higher levels of capacity utilization and greater numbers of physicians in the rural hospital increase the rate of using the nearest rural hospital, or decrease the rate of bypassing to the nearest urban or other hospitals.

A positive coefficient for private insurance (payPrivate) and household median income (HHmedianInc) suggests that patients with private insurance (in contrast to those covered by 
Table 4. Multinomial Logit Model of Hospital Choices by Procedure Type

\begin{tabular}{|c|c|c|c|c|c|c|c|c|c|c|c|c|c|c|c|}
\hline \multirow[b]{3}{*}{ Variables } & \multicolumn{15}{|c|}{ Inpatient } \\
\hline & \multicolumn{3}{|c|}{ Obstetrical procedures } & \multicolumn{3}{|c|}{$\begin{array}{c}\text { Miscellaneous diagnostic \& } \\
\text { Therapeutic Procedures }\end{array}$} & \multicolumn{3}{|c|}{$\begin{array}{c}\text { Operations on the } \\
\text { musculoskeletal system }\end{array}$} & \multicolumn{3}{|c|}{$\begin{array}{c}\text { Operations on the digestive } \\
\text { system }\end{array}$} & \multicolumn{3}{|c|}{$\begin{array}{l}\text { Operations on the cardiovascular } \\
\text { system }\end{array}$} \\
\hline & $\begin{array}{l}\text { Nearest } \\
\text { Urban }\end{array}$ & $\begin{array}{c}\text { Nearest } \\
\text { Rural }\end{array}$ & Other & $\begin{array}{l}\text { Nearest } \\
\text { Urban }\end{array}$ & $\begin{array}{l}\text { Nearest } \\
\text { Rural }\end{array}$ & Other & $\begin{array}{l}\text { Nearest } \\
\text { Urban }\end{array}$ & $\begin{array}{l}\text { Nearest } \\
\text { Rural }\end{array}$ & Other & $\begin{array}{l}\text { Nearest } \\
\text { Urban }\end{array}$ & $\begin{array}{c}\text { Nearest } \\
\text { Rural }\end{array}$ & Other & $\begin{array}{l}\text { Nearest } \\
\text { Urban }\end{array}$ & $\begin{array}{l}\text { Nearest } \\
\text { Rural }\end{array}$ & Other \\
\hline \multicolumn{16}{|l|}{ Demographic } \\
\hline elder65 & & & & -0.082 & 0.309 & -0.227 & -0.009 & -0.117 & 0.126 & -0.037 & 0.137 & -0.099 & 0.05 & -0.061 & 0.011 \\
\hline female & & & & -0.029 & 0.068 & -0.039 & -0.004 & -0.021 & 0.025 & -0.014 & 0.03 & -0.017 & 0.008 & -0.023 & 0.014 \\
\hline nonBlkWht & 0.117 & -0.225 & 0.108 & 0.018 & -0.062 & 0.044 & 0.057 & 0.1 & -0.158 & 0.039 & -0.229 & 0.19 & -0.246 & 0.31 & -0.065 \\
\hline \multicolumn{16}{|l|}{ Choice Characteristics } \\
\hline straightDistance & 0.015 & -0.03 & 0.015 & 0.015 & -0.035 & 0.02 & 0.008 & 0.007 & -0.015 & 0.013 & -0.03 & 0.017 & 0.001 & 0.002 & -0.002 \\
\hline nearHosCapa & -0.002 & 0.006 & -0.004 & 0 & 0.004 & -0.004 & 0 & -0.003 & 0.003 & -0.002 & 0.006 & -0.004 & -0.001 & -0.001 & 0.001 \\
\hline nearHosPhy & -0.002 & 0.007 & -0.004 & -0.002 & 0.003 & -0.001 & -0.004 & -0.002 & 0.005 & -0.002 & 0.005 & -0.003 & 0 & -0.001 & 0.001 \\
\hline \multicolumn{16}{|l|}{ Economics Status } \\
\hline payMedicaidUninsure & 0.067 & -0.092 & 0.024 & 0.039 & 0.797 & -0.047 & 0.023 & -0.019 & -0.005 & 0.017 & 0.003 & -0.02 & 0.07 & -0.071 & 0 \\
\hline HHmedianInc* & 0.107 & -0.152 & 0.045 & 0.063 & -0.084 & 0.021 & 0.088 & -0.066 & -0.022 & 0.12 & -0.173 & 0.052 & 0.132 & -0.097 & -0.035 \\
\hline \multicolumn{16}{|l|}{ Health Status } \\
\hline diagLifeThreaten & 0 & 0 & 0 & 0.005 & -0.023 & 0.017 & -0.083 & 0.027 & 0.056 & 0.071 & -0.124 & 0.053 & 0.056 & -0.004 & -0.052 \\
\hline admissEmergency & 0.006 & 0.088 & -0.094 & 0.134 & -0.136 & 0.002 & -0.08 & 0.331 & 0.047 & 0.048 & -0.099 & 0.051 & -0.1 & 0.085 & 0.015 \\
\hline admissElect & 0.05 & -0.018 & -0.032 & 0.145 & -0.344 & 0.199 & -0.038 & 0.067 & -0.029 & 0.059 & -0.142 & 0.084 & -0.059 & 0.082 & -0.023 \\
\hline complexOper & 0.016 & -0.018 & 0.002 & 0.001 & -0.038 & 0.036 & 0.047 & 0.024 & -0.071 & 0.044 & -0.072 & 0.027 & -0.012 & 0.036 & -0.024 \\
\hline Predicted & & & & & 0517 & 0303 & 0284 & & 0 & 0181 & 040 & 0037 & ( & 0591 & 0020 \\
\hline
\end{tabular}

Notes: The $t$-value is in parenthesis. All coefficients are significant at $5 \%$ significant level. * Type of Admission variable is not available for outpatient data. **Variables not included as explanatory variables for inpatient data. ***elder65, female, and diagLifeThreaten variable are not applicable for the Obstetrical procedure.

Table 4 (Cont'd). Multinomial Logit of Hospital Choices by Procedure Type

\begin{tabular}{|c|c|c|c|c|c|c|c|c|c|}
\hline \multirow[b]{3}{*}{ Variables } & \multicolumn{9}{|c|}{ Outpatient } \\
\hline & \multicolumn{3}{|c|}{ Operations on the eye } & \multicolumn{3}{|c|}{$\begin{array}{c}\text { Operations on the digestive } \\
\text { system }\end{array}$} & \multicolumn{3}{|c|}{$\begin{array}{c}\text { Miscellaneous diagnostic \& } \\
\text { Therapeutic Procedures }\end{array}$} \\
\hline & $\begin{array}{l}\text { Nearest } \\
\text { Urban }\end{array}$ & $\begin{array}{l}\begin{array}{c}\text { Nearest } \\
\text { Rural }\end{array} \\
\end{array}$ & Other & $\begin{array}{l}\begin{array}{l}\text { Nearest } \\
\text { Urban }\end{array} \\
\end{array}$ & $\begin{array}{l}\text { Nearest } \\
\text { Rural }\end{array}$ & Other & $\begin{array}{l}\text { Nearest } \\
\text { Urban }\end{array}$ & $\begin{array}{l}\text { Nearest } \\
\text { Rural }\end{array}$ & Other \\
\hline \multicolumn{10}{|l|}{ Demographic } \\
\hline elder65 & -0.087 & 0.2 & -0.112 & -0.043 & 0.151 & -0.108 & -0.059 & -0.214 & 0.272 \\
\hline $\begin{array}{l}\text { female } \\
\text { nonBlkWht }\end{array}$ & -0.017 & 0.029 & -0.012 & -0.004 & 0.006 & -0.002 & -0.007 & -0.013 & 0.02 \\
\hline \multicolumn{10}{|l|}{ Choice Characteristics } \\
\hline straightDistance & 0.008 & -0.027 & 0.019 & 0.014 & -0.035 & 0.021 & 0.01 & 0.011 & -0.021 \\
\hline nearHosCapa & -0.001 & 0.002 & -0.001 & -0.001 & 0.002 & -0.001 & 0.002 & 0.001 & -0.004 \\
\hline nearHosPhy & -0.001 & 0.004 & -0.003 & -0.002 & 0.005 & -0.003 & -0.002 & -0.003 & 0.005 \\
\hline \multicolumn{10}{|l|}{ Economics Status } \\
\hline payMedicaidUninsure & -0.022 & -0.072 & 0.094 & -0.016 & 0.064 & -0.048 & -0.061 & -0.185 & 0.247 \\
\hline \multirow{2}{*}{\multicolumn{10}{|c|}{ Health Status }} \\
\hline & & & & & & & & & \\
\hline $\begin{array}{l}\text { diagLifeThreaten } \\
\text { admissmergency } \\
\text { admissElect } \\
\text { complexOper } \\
\text { Predicted }\end{array}$ & 0.28 & -0.265 & -0.016 & 0.025 & -0.048 & 0.023 & -0.042 & -0.007 & 0.048 \\
\hline Probabilities & 0.089 & 0.526 & 0.385 & 0.136 & 0.585 & 0.279 & 0.182 & 0.454 & 0.364 \\
\hline
\end{tabular}

C Southern Regional Science Association 2010. 
public insurance or uninsured) ${ }^{10}$ and higher income households are likely to choose the nearest urban hospital or other hospitals rather than their nearest rural hospital. This result is not surprising because patients with greater financial resources are more able to travel further in search of better hospital care. However, for the Outpatient Model the opposite effect for private insurance is found. This result suggests that for outpatient visits, patients with private insurance tend to choose their nearest rural hospital compared to other choices. The household income coefficient is positive in the outpatient models, implying that higher income households more likely bypass the nearest rural hospital in favor of other hospitals.

Under the Inpatient model, our indicators for elective and emergency admissions (admissElect and admissEmergency), life threatening diagnosis (diagLifeThreaten), and complex procedures (comlexOper) have positive coefficients, implying that inpatients admitted to a hospital with these issues are more likely to have chosen the nearest urban hospital relative to the nearest rural hospital.

In general, the patterns of characteristics for hospital choice discussed for inpatient services are similar for the outpatient bypass situation, although the types of procedures treated may be different. The miscellaneous diagnostic and therapeutic procedures have negative coefficients, suggesting that outpatients tend to prefer their nearest rural hospital for therapeutic and less routine procedures. In contrast, for procedures related to the digestive system, outpatients tend to choose the nearest urban hospital rather than the nearest rural hospital. This could reflect the level of complication associated with each procedure and the patients' perception of the rural hospital's ability to handle them. Complicated procedures are more likely to be handled by other or urban hospitals rather than by the nearest rural hospital.

Eye-related procedures have negative coefficients for the nearest urban hospital and positive coefficients for other hospitals. This suggests that urban hospitals are less likely to treat rural residents for this type of procedure. Hospital specialization and availability of services may also be major causes of this result.

As mentioned earlier, examining marginal effects can provide a more intuitive interpretation for these results. Table 5 and Table 6 illustrate the marginal effects of the full inpatient and outpatient models and of the procedures' models respectively.

The interpretation of the results given in Table 5 and Table 6 is straightforward. A positive (negative) marginal effect means that the variable has a positive (negative) impact on the probability of making that particular hospital choice. When evaluated at their mean values, only elder65, female, nearHosCapa, nearHosPhy and procEye in Table 4 have positive marginal effects with respect to the nearest rural hospital, implying that elderly and female patients tend to utilize their nearest rural hospitals. Also, an increase in hospital capacity ratio and in the number of physicians tends to increase in the probability of choosing the nearest rural hospital. Other variables, including HHmedianInc and diagLifeThreaten in both the Inpatient and the Outpatient models, admissEmergency, admissElect and complexOper in the Inpatient model, and procDiges and procThera in the Outpatient model have positive marginal effects with respect to other

\footnotetext{
${ }^{10}$ There was a concern regarding the actual numbers of low-income patients who were uninsured and admitted as inpatients via the emergency type of admission because they could create a misleading result if their admissions were not truly for emergency purposes. Upon investigation, however, the share of uninsured inpatients among emergency-type admissions is only 4 percent.
}

(C) Southern Regional Science Association 2010. 
Table 5. Marginal Effects and Predicted Probabilities for Hospital Choice

\begin{tabular}{|c|c|c|c|c|c|c|}
\hline \multirow[b]{2}{*}{ Variables } & \multicolumn{3}{|c|}{ Inpatient } & \multicolumn{3}{|c|}{ Outpatients } \\
\hline & $\begin{array}{l}\text { Nearest } \\
\text { Urban }\end{array}$ & $\begin{array}{c}\text { Nearest } \\
\text { Rural }\end{array}$ & Others & $\begin{array}{l}\text { Nearest } \\
\text { Urban }\end{array}$ & $\begin{array}{c}\text { Nearest } \\
\text { Rural }\end{array}$ & Others \\
\hline \multicolumn{7}{|l|}{ Demographic } \\
\hline elder 65 & -0.034 & 0.147 & -0.113 & -0.044 & 0.164 & -0.120 \\
\hline female & -0.032 & 0.070 & -0.039 & -0.011 & 0.026 & -0.015 \\
\hline nonBlkWht & 0.048 & -0.233 & 0.185 & & & \\
\hline \multicolumn{7}{|l|}{ Choice Characteristics } \\
\hline straightDistance & 0.013 & -0.031 & 0.018 & 0.012 & -0.030 & 0.018 \\
\hline nearHosCapa & -0.001 & 0.005 & -0.003 & -0.001 & 0.001 & -0.001 \\
\hline nearHosPhy & -0.002 & 0.004 & -0.002 & -0.002 & 0.005 & -0.003 \\
\hline \multicolumn{7}{|l|}{ Economics Status } \\
\hline payMedicaidUninsure & 0.042 & -0.051 & 0.009 & -0.020 & 0.064 & -0.044 \\
\hline HHmedianInc* & 0.110 & -0.142 & 0.032 & 0.107 & -0.124 & 0.018 \\
\hline \multicolumn{7}{|l|}{ Health Status } \\
\hline diagLifeThreaten & 0.059 & -0.128 & 0.069 & 0.077 & -0.106 & 0.029 \\
\hline admissEmergency & 0.005 & -0.037 & 0.032 & & & \\
\hline admissElect & 0.073 & -0.175 & 0.102 & & & \\
\hline complexOper & 0.056 & -0.118 & 0.062 & & & \\
\hline procEye & & & & -0.048 & 0.153 & -0.105 \\
\hline procDiges & & & & -0.007 & -0.099 & 0.106 \\
\hline procThera & & & & -0.066 & 0.026 & 0.040 \\
\hline Predicted Probabilities & 0.179 & 0.504 & 0.317 & 0.157 & 0.500 & 0.343 \\
\hline
\end{tabular}

hospitals (negative marginal effects with respect to the patients' nearest rural hospital), implying that bypassing is more likely.

The last line in both Table 5 and Table 6 shows the predicted probability of patients making different hospital choices calculated using the mean values of all variables. The predicted probability of choosing the nearest rural hospital is approximately 50 percent in both overall models. The probability of choosing the nearest urban hospital is higher for the Inpatient model than for the Outpatient model (17.9 percent vs. 15.7 percent) and the probability of choosing other hospitals is lower for the Inpatient model than for the Outpatient model (31.7 percent vs. 34.3 percent). Based on these predicted probabilities, rural residents are more likely to bypass

their nearest rural hospital in favor of their nearest urban hospital for outpatient procedures than for inpatient procedures. The probability of choosing the nearest rural hospital is slightly lower for outpatients; hence, the bypassing behavior appears to occur more in the outpatient category than in the inpatient category.

\section{CONCLUSIONS AND POLICY IMPLICATIONS}

This study uses Iowa Hospital Association records on inpatient and outpatient procedures at rural Iowa hospitals to examine how institutional, location, and individual characteristics affect choices of hospitals for rural residents. We analyze five categories of inpatient procedures and three categories of outpatient procedures individually and collectively to evaluate factors affecting the choice of local versus non-local hospitals for these services.

Consistent with previous studies, we find that the rural residents most likely to bypass their local hospitals are younger people with private insurance (for outpatient) and those already living a long distance from a hospital. Complex procedures and life-threatening illnesses reduce the probability of choosing the nearest rural hospital. Rural residents appear less likely to bypass the nearest rural hospital for outpatient services. This general pattern was consistent for the 
Table 6. Marginal Effects and Predicted Probabilities for Hospital Choice by Procedure Type

\begin{tabular}{|c|c|c|c|c|c|c|c|c|c|c|c|c|c|c|c|}
\hline \multirow[b]{3}{*}{ Variables } & \multirow{2}{*}{\multicolumn{3}{|c|}{ Obstetrical procedures }} & \multirow{2}{*}{\multicolumn{3}{|c|}{$\begin{array}{c}\text { Miscellaneous diagnostic \& } \\
\text { Therapeutic Procedures }\end{array}$}} & \multirow{2}{*}{\multicolumn{3}{|c|}{$\begin{array}{c}\text { Inpatient } \\
\begin{array}{c}\text { Operations on the } \\
\text { musculoskeletal system }\end{array}\end{array}$}} & \multirow{2}{*}{\multicolumn{3}{|c|}{$\begin{array}{c}\begin{array}{c}\text { Operations on the digestive } \\
\text { system }\end{array} \\
\end{array}$}} & \multirow{2}{*}{\multicolumn{3}{|c|}{$\begin{array}{c}\text { Operations on the } \\
\text { cardiovascular system }\end{array}$}} \\
\hline & & & & & & & & & & & & & & & \\
\hline & $\begin{array}{c}\text { Nearest } \\
\text { Urban }\end{array}$ & $\begin{array}{c}\text { Nearest } \\
\text { Rural }\end{array}$ & Other & $\begin{array}{c}\text { Nearest } \\
\text { Urban }\end{array}$ & $\begin{array}{c}\text { Nearest } \\
\text { Rural }\end{array}$ & Other & $\begin{array}{c}\text { Nearest } \\
\text { Urban }\end{array}$ & $\begin{array}{c}\text { Nearest } \\
\text { Rural }\end{array}$ & Other & $\begin{array}{c}\text { Nearest } \\
\text { Urban }\end{array}$ & $\begin{array}{c}\text { Nearest } \\
\text { Rural }\end{array}$ & Other & $\begin{array}{c}\text { Nearest } \\
\text { Urban }\end{array}$ & $\begin{array}{c}\text { Nearest } \\
\text { Rural }\end{array}$ & Other \\
\hline \\
\hline elder65 & & & & $\begin{array}{l}-0.082 \\
-0.029\end{array}$ & $\begin{array}{l}0.309 \\
0.068\end{array}$ & $\begin{array}{l}-0.227 \\
-0.039\end{array}$ & $\begin{array}{l}-0.009 \\
-0.004\end{array}$ & $\begin{array}{l}-0.1177 \\
-0.021\end{array}$ & 0.126 & ${ }^{-0.037}$ & 0.137 & -0.099 & $\begin{array}{l}0.050 \\
-0.08\end{array}$ & -0.061 & 0.011 \\
\hline $\begin{array}{l}\text { female } \\
\text { nonBlkWht }\end{array}$ & 0117 & -0225 & 0.108 & $\begin{array}{c}-0.029 \\
0.018\end{array}$ & $\begin{array}{r}0.068 \\
-0.062\end{array}$ & $\begin{array}{r}-0.039 \\
0.044\end{array}$ & $\begin{array}{r}-0.004 \\
0.057\end{array}$ & $\begin{array}{l}-0.021 \\
0.100\end{array}$ & $\begin{array}{c}0.025 \\
-0.158\end{array}$ & $\begin{array}{l}-0.014 \\
0.039\end{array}$ & $\begin{array}{r}0.030 \\
-0.229\end{array}$ & $\begin{array}{r}-0.017 \\
0.190\end{array}$ & $\begin{array}{l}0.008 \\
-046\end{array}$ & -0.023 & 0.014 \\
\hline \multicolumn{15}{|l|}{$\begin{array}{l}\text { noice Characteristics } \\
\text { Cho }\end{array}$} & \\
\hline straightDistance & 0.015 & -0.030 & 0.015 & 0.015 & -0.035 & 0.020 & 0.008 & 0.007 & -0.015 & 0.013 & -0.030 & 0.017 & 0.001 & 0.002 & -0.002 \\
\hline nearHosCapa & -0.002 & 0.006 & -0.004 & 0.000 & 0.004 & -0.004 & 0.000 & -0.003 & 0.003 & -0.002 & 0.006 & -0.004 & -0.001 & -0.001 & 0.001 \\
\hline \multirow{2}{*}{\multicolumn{16}{|c|}{ Economics Status }} \\
\hline & & & & & & & & & & & & & & & \\
\hline payMedicaidUninsure & 0.067 & -0.092 & 0.024 & 0.039 & 0.797 & -0.047 & 0.023 & -0.019 & -0.005 & 0.017 & 0.003 & -0.020 & 0.070 & -0.071 & 0.000 \\
\hline \multirow{2}{*}{\multicolumn{16}{|c|}{ Health Status }} \\
\hline & & & & & & & & & & & & & & & \\
\hline diagLifeThreaten & $\begin{array}{l}0.000 \\
0.006\end{array}$ & $\begin{array}{l}0.000 \\
0.088\end{array}$ & 0.000 & 0.005 & -0.023 & 0.017 & -0.083 & 0.027 & 0.056 & 0.071 & -0.124 & 0.053 & 0.056 & -0.004 & -0.052 \\
\hline $\begin{array}{l}\text { admissEmergency } \\
\text { admissFlect }\end{array}$ & $\begin{array}{l}0.006 \\
0.050\end{array}$ & $\begin{array}{c}0.088 \\
-0.018\end{array}$ & $\begin{array}{l}-0.094 \\
-0.032\end{array}$ & 0.134 & $\begin{array}{l}-0.136 \\
-0.344\end{array}$ & $\begin{array}{l}0.002 \\
0.199\end{array}$ & $\begin{array}{l}-0.080 \\
-0.038\end{array}$ & $\begin{array}{l}0.331 \\
0.067\end{array}$ & 0.047 & $\begin{array}{l}0.048 \\
0.059\end{array}$ & -0.099 & 0.051 & $\begin{array}{l}-0.100 \\
-0.059\end{array}$ & 0.085 & 0.015 \\
\hline $\begin{array}{l}\text { admissetect } \\
\text { complexOper }\end{array}$ & $\begin{array}{l}0.050 \\
0.016\end{array}$ & $\begin{array}{l}-0.018 \\
-0.018\end{array}$ & $\begin{array}{r}-0.032 \\
0.002\end{array}$ & $\begin{array}{l}0.145 \\
0.001\end{array}$ & $\begin{array}{l}-0.344 \\
-0.038\end{array}$ & $\begin{array}{l}0.199 \\
0.036\end{array}$ & $\begin{array}{l}-0.038 \\
0.047\end{array}$ & $\begin{array}{l}0.067 \\
0.024\end{array}$ & $\begin{array}{l}-0.029 \\
-0.071\end{array}$ & $\begin{array}{l}0.059 \\
0.044\end{array}$ & $\begin{array}{l}-0.142 \\
-0.072\end{array}$ & $\begin{array}{l}0.084 \\
0.027\end{array}$ & $\begin{array}{r}-0.0399 \\
-0.012\end{array}$ & $\begin{array}{l}0.082 \\
0.036\end{array}$ & $\begin{array}{l}-0.023 \\
-0.024\end{array}-3$ \\
\hline $\begin{array}{l}\text { procEye } \\
\text { procDiges } \\
\text { procThera }\end{array}$ & & & & & & & & & & & & & & & \\
\hline Predicted Probabilities & 0.163 & 0.476 & 0.361 & 0.180 & 0.517 & 0.303 & 0.344 & 0.460 & 0.196 & 0.181 & 0.494 & 0.325 & 0.442 & 0.524 & 0.034 \\
\hline
\end{tabular}

Table 6. Marginal Effects and Predicted Probabilities

for Hospital Choice by Procedure Type (Cont'd)

\begin{tabular}{|c|c|c|c|c|c|c|c|c|c|}
\hline \multirow[b]{3}{*}{ Variables } & \multicolumn{9}{|c|}{ Outpatient } \\
\hline & \multicolumn{3}{|c|}{ Operations on the eye } & \multicolumn{3}{|c|}{$\begin{array}{c}\text { Operations on the digestive } \\
\text { system }\end{array}$} & \multicolumn{3}{|c|}{$\begin{array}{l}\text { Miscellaneous diagnostic \& } \\
\text { Therapeutic Procedures }\end{array}$} \\
\hline & $\begin{array}{c}\text { Nearest } \\
\text { Urban }\end{array}$ & $\begin{array}{c}\text { Nearest } \\
\text { Rural }\end{array}$ & Other & $\begin{array}{l}\text { Nearest } \\
\text { Urban }\end{array}$ & $\begin{array}{c}\text { Nearest } \\
\text { Rural }\end{array}$ & Other & $\begin{array}{c}\text { Nearest } \\
\text { Urban }\end{array}$ & $\begin{array}{c}\text { Nearest } \\
\text { Rural }\end{array}$ & Other \\
\hline \multicolumn{10}{|l|}{ Demographic } \\
\hline elder65 & -0.087 & 0.200 & -0.112 & -0.043 & 0.151 & -0.108 & -0.059 & -0.214 & 0.272 \\
\hline female & -0.017 & 0.029 & -0.012 & -0.004 & 0.006 & -0.002 & -0.007 & -0.013 & 0.020 \\
\hline \multicolumn{10}{|l|}{ Choice Characteristics } \\
\hline straightDistance & 0.008 & -0.027 & 0.019 & 0.014 & -0.035 & 0.021 & 0.010 & 0.011 & -0.021 \\
\hline nearHosc Capa & -0.001 & 0.002 & -0.001 & -0.001 & 0.002 & -0.001 & 0.002 & 0.001 & -0.004 \\
\hline \multirow{2}{*}{\multicolumn{10}{|c|}{$\begin{array}{l}\text { Economics Status } \\
\text { E }\end{array}$}} \\
\hline & & & & & & & & & \\
\hline payMedicaidUninsure & -0.022 & -0.072 & 0.094 & -0.016 & 0.064 & -0.048 & -0.061 & -0.185 & 0.247 \\
\hline $\begin{array}{l}\text { HHedianInc* } \\
\text { HHe }\end{array}$ & 0.084 & -0.037 & -0.048 & 0.113 & -0.148 & 0.035 & 0.015 & 0.057 & -0.073 \\
\hline \multicolumn{9}{|l|}{ Health Status } & \\
\hline $\begin{array}{l}\text { diagLifeThreaten } \\
\text { admissEmergency } \\
\text { admissElect } \\
\text { complexOper } \\
\text { procEye } \\
\text { procDiges } \\
\text { procThera }\end{array}$ & 0.280 & -0.265 & -0.016 & 0.025 & -0.048 & 0.023 & -0.042 & -0.007 & 0.048 \\
\hline Predicted Probabilities & 0.089 & 0.526 & 0.385 & 0.136 & 0.585 & 0.279 & 0.182 & 0.454 & 0.364 \\
\hline
\end{tabular}

(C) Southern Regional Science Association 2010. 
separately-evaluated outpatient eye and digestive-tract procedures, but less so for the miscellaneous category of procedures.

This study differs from previous work in that the data and analysis allows us to examine the manner in which characteristics of hospitals and rural residents are affecting hospital choices with respect to inpatient and outpatient procedures and to categories of medical procedures. While the aggregated inpatient and outpatient results are similar to those from previous studies, the more detailed analysis indicates that the probability of bypassing rural hospitals increased for inpatient cardiovascular procedures and for outpatient miscellaneous procedures.

Decisions by rural residents to bypass their nearest hospitals have implications for the financial well-being of rural hospitals. While Critical Access Hospitals in rural areas benefit from cost-based reimbursements, continued population loss in rural areas and hospital-bypassing behavior are resulting in fewer patient visits, suggesting that rural hospitals face increased financial pressures in the future.

Demographic changes in rural areas add to the uncertainties faced by rural hospitals. While the current elderly population base appears more likely to use rural hospitals, more research is needed to assess how future cohorts of elderly patients in rural areas will relate to rural hospitals. Iowa, like other Midwestern states, has seen a growth in the Hispanic population of nonmetropolitan areas. Our results suggest that this population growth may not offer opportunities for rural hospitals as this demographic is more likely to bypass rural hospitals in favor of urban ones.

The argument that rural hospitals are necessary and important for providing access to emergency health care services is challenged by our results. In spite of the accessibility and community development arguments for rural hospitals, our results show that inpatients with emergency admission are more likely to bypass local rural hospitals and instead choose the nearest urban hospitals.

The bypass problem appears more pronounced for inpatient visits than for outpatient visits, consistent with the reorientation toward acute health-care services that many rural hospitals are undertaking. Modeling inpatient and outpatient separately suggests several potential strategies for health policy planners coping with patient outmigration problems. For example, it suggests that isolation is a barrier that keeps rural residents from bypassing local rural hospitals. Thus, strategies that bring more specialty services, such as visiting-specialist services, telemedicine, Critical Access Hospitals, etc., to rural locations could enhance both perceptions and quality of care could mitigate patient bypassing of rural hospitals.

Local health care providers are not the only rural service category being affected by such bypassing behavior of rural residents. Smaller rural communities have been battling the consolidation of retailing and consumer services into larger trade centers for decades. To the degree that marketing and development strategies effectively address market leakages for these other services, they might also be applied to address similar health care issues.

\section{REFERENCES}

Adams, E. Kathleen, Robert Houchens, George E. Wright, and James Robbins. (1991) "Predicting Hospital Choice for Rural Medicare Beneficiaries: The Role of Severity of Illness," Health Services Research, 26, 538-612.

(C) Southern Regional Science Association 2010. 
Bronstein, Janet M. and Michael A. Morrisey. (1990) "Determinants of Rural Travel Distance for Obstetrics Care," Medical Care, 28, 853-866.

Capalbo, Susan M. and Christine N. Heggem. (1999) "Innovations in the Delivery of Health Care Services to Rural Communities Telemedicine and Limited-Service Hospitals," Rural Development Perspectives, 14(3), 8-13.

Cordes, Sam M. (1997) "Health Care and Rural Economic Development: Historic Linkages and Future Growth Potential," unpublished paper presented to National Rural Renaissance Task Force, Roslyn, VA, June 2.

Goodman, David C., Elliott Fisher, Thérèse A. Stukel, and Chiang-hua Chang. (1997) "The Distance to Community Medical Care and Likelihood of Hospitalization: Is Closer Always Better?," American Journal of Public Health, 87, 1144-1150.

Greene, William H. (2000) Econometric Analysis, $4^{\text {th }}$ ed. Prentice-Hall Inc.: Upper Saddle River, NJ.

Hausman, Jerry and Daniel McFadden. (1984) "Specification Test for the Multinomial Logit Model," Econometrica, 52, 1219-1240.

Hogan, Christopher. (1988) "Patterns of Travel for Rural Individuals Hospitalized in New York State: Relationships between Distance, Destination and Case Mix," Journal of Rural Health, 4(2), 29-41.

Imerman, Mark, Liesl Eathington, Kanlaya Jintanakul, and Dan Otto. (2004) "Hospital Utilization, Changing Demographics, and Implications for Rural Health Care Services," unpublished paper, Iowa State University, July 15. Last accessed on September 15, 2010, at http://www.idph.state.ia.us/hpcdp/common/pdf/health_care_access/project a.pdf.

Iowa Hospital Association. (2003) January 2002-December 2002 Outpatient Databases.

Lawrence, Kevin, Joe Townsel, Gerius Patterson, Tricia Davis, and Linda Moscoe. (2003) "Trends in Rural Hospital Closure: 1990-2000," OEI 04-02-00610, Office of Inspector General, U.S. Department of Health and Human Services, May.

Liu, Jiexin, Gail Bellamy, and Melissa McCormick. (2007) "Patient Bypass Behavior and Critical Access Hospitals: Implications for Patient Retention,” Journal of Rural Health, 23(1), 17-24

McNamara, Paul E. (1998) "Rural Residents' Demand for Hospital Services: An Empirical Analysis of Patient Outmigration and Geographic Accessibility," Ph.D. dissertation, University of Minnesota.

Morgan, Tanya J., Lori W. Turner, and Lucy A. Savitz. (1999) "Factors Influencing Obstetrical Care Selection," American Journal of Health Studies, 15, 100-106.

Office of Technology Assessment. (1990) Health Care in Rural America, OTA-H-434, U.S. Congress, (U.S. Government Printing Office: Washington, DC) September

Phibbs, Ciaran and Harold S. Luft. (1995) "Correlation of Travel Time on Roads versus Straight Line Distance," Medical Care Research Review, 52, 532-542.

Radcliff, Tiffany, Michelle Brasure, Ira S. Moscovice, and Jeffrey T. Stensland. (2003) "Understanding Rural Hospital Bypass Behavior," Journal of Rural Health, 19, 252-259.

(C) Southern Regional Science Association 2010. 